\title{
Current Approach to Non-Infectious Pulmonary Complications of Hematopoietic Stem Cell Transplantation
}

\author{
Güldane Cengiz Seval, Pervin Topçuoğlu, Taner Demirer
}

Department of Hematology, Ankara University School of Medicine, Cebeci Hospital, Ankara, Turkey

Hematopoietic stem cell transplantation is an established treatment for patients with a wide range of malignant and nonmalignant conditions. Noninfectious pulmonary complications still remain a leading cause of morbidity and mortality in these patients. Treating hematopoietic stem cell transplantation recipients with noninfectious pulmonary complications is still challenging, and the current treatment armamentarium and strategies are not adequate for patients receiving hematopoietic stem cell transplantation. Further trials are needed for a better description of the pathogenesis and the complete diagnostic criteria as well as for the development of effective therapeutic approaches for the management of noninfectious pulmonary complications of the hematopoietic stem cell transplantation. This review outlines the incidence, risk factors, pathogenesis, and clinical spectrum and discusses the current approaches to the management of noninfectious pulmonary complications of Hematopoietic stem cell transplantation.

Keywords: Hematopoietic stem cell transplantation, pulmonary complications, Bronchiolitis Obliterans syndrome, Idiopathic Pneumonia syndrome
Hematopoietic stem cell transplantation (HSCT) has been increasingly used for the treatment of a wide range of benign and malignant disorders (1-5). However, HSCT is still limited due to the development of serious complications associated with the occurrence of either acute or chronic graft versus host disease (aGVHD, cGVHD). Advances in the pretransplant conditioning regimens and post-transplant immunosuppression have contributed to improved overall survival (6). Despite these advancements, pulmonary complications still develop in 30\%$60 \%$ of HSCT recipients and can account for approximately $50 \%$ of transplant-related mortality $(6,7)$. The timeline of the primary pulmonary complications following HSCT is shown in Figure 1. Factors that influence the development of pulmonary complications in HSCT include an underlying disease, the age of the patient, previous infections (pretransplant serostatus), the conditioning regimen, current or prior immunosuppressive and radiation treatment, the type of stem cell transplant (autologous/ allogeneic), the use of prophylactic antibiotics, and the time passed on the transplant (7-12). In recent years, the spectrum of pulmonary complications following HSCT has changed increasingly from infectious to noninfections etiologies with the judicious use of broad-spectrum antimicrobial prophylaxis (13). The approach for the evaluation of pulmonary complications occurring after allogeneic HSCT depends on the post-transplant time interval and the engraftment status of HSCT recipients. Since most of the treatable pulmonary complications in patients are diagnosed noninvasively and frequently via bronchoscopy, a surgical lung biopsy is rarely needed. Restrictive and obstructive ventilatory defects and gas transfer abnormalities have been observed frequently after HSCT $(13,14)$. Several research groups have demonstrated the correlation between pretransplant pulmonary function test (PFT) abnormalities and the risk of respiratory failure in various cohorts $(15,16)$. In a study of 52 young, asymptomatic patients, $23 \%$ had restrictive defects with or without impaired gas transfer and $15 \%$ had isolated impaired gas transfer before HSCT (13). However, the role of PFT in identifying HSCT recipients at risk for respiratory failure needs validation through larger prospective studies. This review also discusses the PFT findings of pulmonary complications. Noninfectious pulmonary complications still remain a significant problem following HSCT, in both acute and chronic settings. In approximately $50 \%$ of cases, no infectious microorganisms

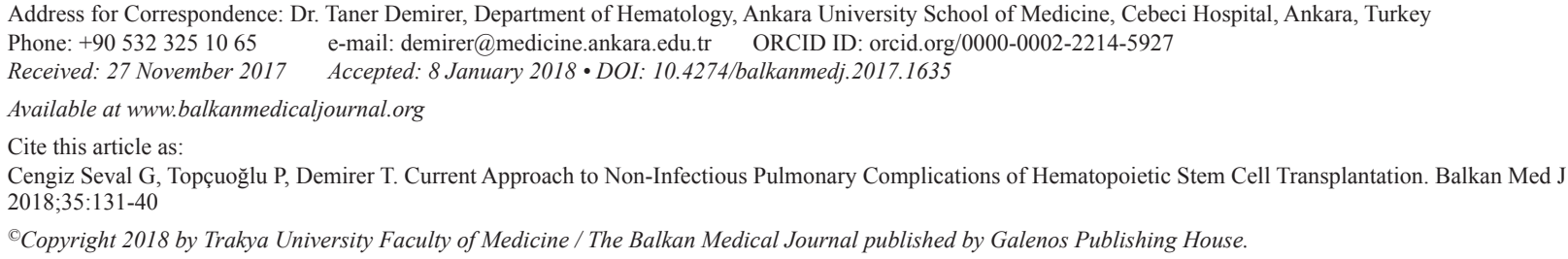


are identified in the lungs of affected patients (17). It is important to note that this type of complications is associated with significant morbidity and mortality and poor response to standard treatments. Periengraftment Respiratory Distress syndrome (PERDS), diffuse alveolar hemorrhage (DAH), Idiopathic Pneumonia syndrome (IPS), bronchiolitis obliterans organizing pneumonia (BOOP), and Bronchiolitis Obliterans syndrome (BOS) are all unique subsets of noninfectious complications (Table 1) (18). To our knowledge, there is no

\begin{tabular}{|c|c|c|}
\hline $\begin{array}{l}\text { Phase I } \\
\text { Pre-engraftment ( } 0-30 \text { days) }\end{array}$ & $\begin{array}{l}\text { Phase II } \\
\text { Post-engraftment (30-100 } \\
\text { days) }\end{array}$ & $\begin{array}{l}\text { Phase III } \\
\text { Late phase (>100 days) }\end{array}$ \\
\hline $\begin{array}{l}\text { Neutropenia, barrier } \\
\text { breakdown } \\
\text { Acute GVHD }\end{array}$ & $\begin{array}{l}\text { Impaired cellular and } \\
\text { humoral immunity } \\
\text { Acute GVHD }\end{array}$ & $\begin{array}{l}\text { Impaired humoral and } \\
\text { cellular immunity } \\
\text { Chronic GVHD }\end{array}$ \\
\hline \multirow[t]{2}{*}{$\mathrm{CHF}$} & & PVOD \\
\hline & DPTS & \\
\hline \multirow[t]{4}{*}{ PERDS } & & BOS \\
\hline & \multirow[t]{2}{*}{ DAH } & \multirow[b]{2}{*}{ PTLPD } \\
\hline & & \\
\hline & \multicolumn{2}{|c|}{ BOOP } \\
\hline & IPS & \\
\hline \multicolumn{2}{|r|}{ PCT } & \\
\hline
\end{tabular}

FIG. 1. The timeline of the primary pulmonary complications following [Chi et al. (19)].

BOS: Bronchiolitis Obliterans syndrome; BOOP: bronchiolitis obliterans organizing pneumonia; CHF: congestive heart failure; DAH: diffuse alveolar hemorrhage; DPTS: Delayed Pulmonary Toxicity syndrome; GVHD: graft versus host disease IPS: Idiopathic Pneumonia syndrome; PCT: pulmonary cytolytic thrombi; PERDS: Periengraftment Respiratory Distress syndrome; PTLPD: post-transplant lymphoproliferative disorder; PVOD: pulmonary veno-occlusive disease standard guideline regarding an approach to the management of pulmonary complications following HSCT. In addition, due to the availability of limited prospective controlled studies assessing the efficacy of different treatments, no standard therapy can be recommended. A suggested algorithmic approach to the management of pulmonary complications after HSCT is outlined in Figure 2. This review focuses on the definition, risk factors, and pathogenesis of the primary noninfectious pulmonary complications in HSCT recipients.

\section{IDIOPATHIC PNEUMONIA SYNDROME}

IPS is an important cause of acute pulmonary complications after HSCT. In 1993, a panel consensus by the National Institutes of Health (NIH) clarified IPS as a widespread alveolar injury following HSCT in the absence of active lower respiratory tract infection or cardiogenic causes (20). Recently, in 2011, the American Thoracic Society updated the diagnostic criteria of IPS (21). From a practical standpoint, the definition of IPS depends on the exclusion of infectious organisms, cardiac failure, acute renal insufficiency, or iatrogenic fluid overload in the setting of lung injury following HSCT. IPS encompasses a heterogeneous entity of disorders that results from common pathological findings of acute interstitial pneumonitis, DAH, PERDS, and Delayed Pulmonary Toxicity syndrome (DPTS); chemotherapy-related lung injury (21). The etiology and pathogenesis of IPS have not been well defined. Various studies have shown that the incidence of IPS ranges from 3\% to $15 \%$, and these complications generally occur within 4 months after allogeneic HSCT with myeloablative conditioning $(22,23)$. In

TABLE 1. The distinguishing characteristics of the noninfectious pulmonary complications in hematopoietic stem cell transplantation

\begin{tabular}{|c|c|}
\hline $\begin{array}{l}\text { Noninfectious pulmonary } \\
\text { complications }\end{array}$ & Distinguishing characteristics \\
\hline PERDS & $\begin{array}{l}\text { Early/acute within } 96 \mathrm{~h} \text { of neutrophil recovery, more common in autologous HSCT recipients, diffuse pulmonary infiltrates, } \\
\text { absence of cardiac insufficiency, an erythematous maculopapular rash (not attributable to drugs) and no identified infectious } \\
\text { etiology, excellent response to glucocorticoids, favorable prognosis }\end{array}$ \\
\hline DAH & $\begin{array}{l}\text { Early/acute onset, diffuse pulmonary infiltrates, progressive bloodier return of BAL fluid without frank hemoptysis, the presence } \\
\text { of }>20 \% \text { hemosiderin-laden macrophages in BAL fluid, absence of infections, poor prognosis }\end{array}$ \\
\hline IPS & $\begin{array}{l}\text { Late/subacute onset, more common in allogeneic HSCT recipients, progressive respiratory failure, diagnosed by exclusion of other } \\
\text { causes, lung biopsy showing diffuse alveolar damage or interstitial pneumonitis, poor response to corticosteroids, poor prognosis }\end{array}$ \\
\hline BOS & $\begin{array}{l}\text { Late onset ( } 1 \text { year), more common in allogeneic HSCT recipients, absence of fever, normal radiologic findings, hyperinflated, } \\
\text { air trapping, bronchiectasis, airflow obstruction, normal diffusion capacity, moderate response to corticosteroids and } \\
\text { immunosuppressive, poor prognosis, progressive disease with high mortality }\end{array}$ \\
\hline BOOP & $\begin{array}{l}\text { Usually within the first } 100 \text { days, patchy pulmonary airspace consolidation with fever, nonproductive cough, and dyspnea; lung } \\
\text { biopsy is the gold standard for diagnosis, good response to prolonged corticosteroid treatment courses, potentially reversible }\end{array}$ \\
\hline DPTS & $\begin{array}{l}\text { Late/subacute onset, occurs in autologous HSCT recipients following conditioning regimens containing cyclophosphamide, } \\
\text { cisplatin, etoposide, and bischloroethylnitrosurea, good response to glucocorticoids, good prognosis }\end{array}$ \\
\hline PCT & $\begin{array}{l}\text { Late/subacute onset, fever, and numerous peripheral pulmonary nodules on chest CT in children with GVHD, lung biopsy } \\
\text { showing necrotic, basophilic thromboembolism with entrapped monocytes, no proven therapy, good prognosis }\end{array}$ \\
\hline
\end{tabular}




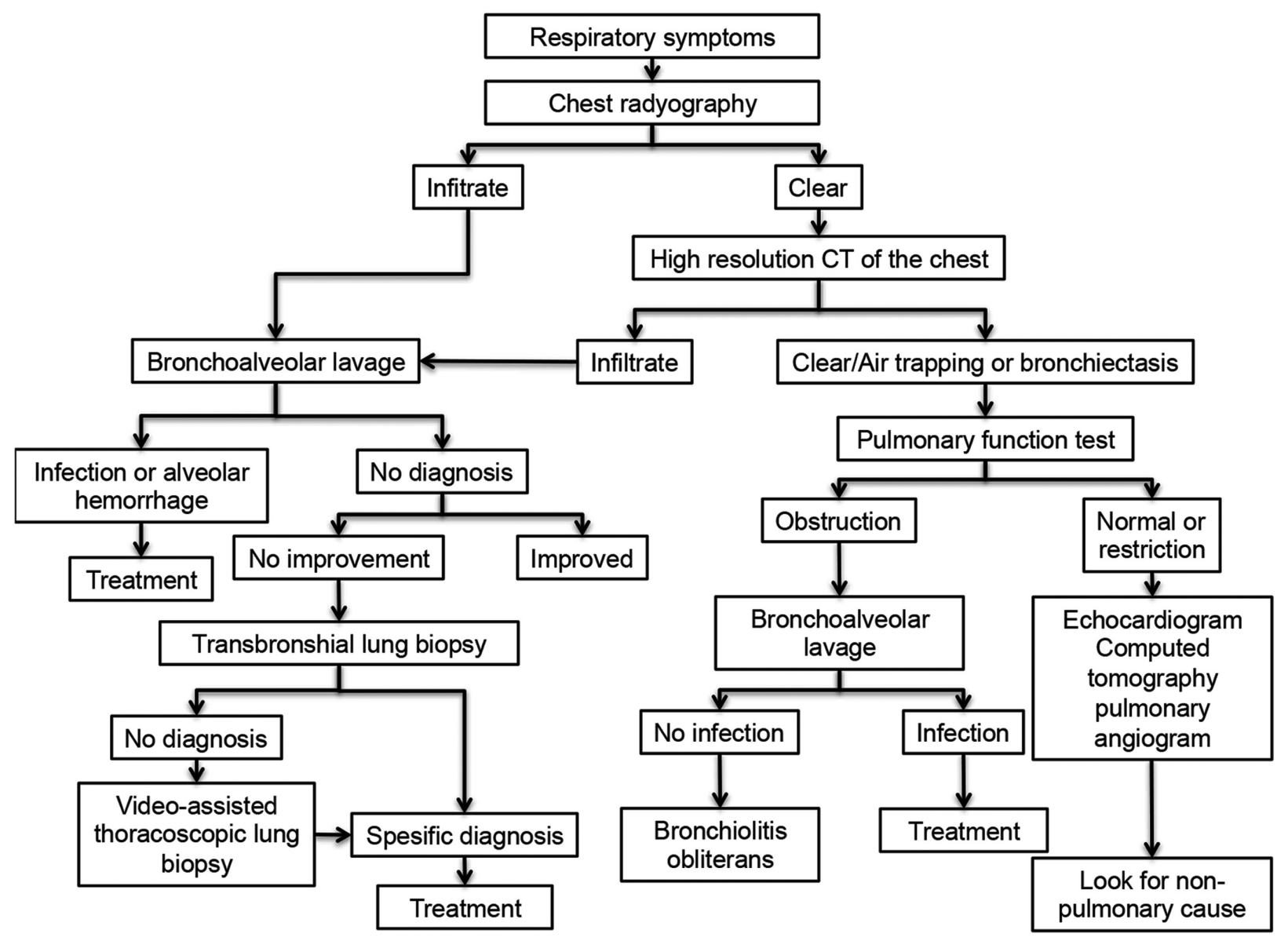

FIG. 2. An algorithmic approach to the management of pulmonary complications after hematopoietic stem cell transplantation [Afessa et al. (7)].

2003, Fukuda et al. (24) found a significantly lower cumulative incidence of IPS in patients at 120 days after nonmyeloablative conditioning ( $2.2 \%$ vs. $8.4 \%$; $\mathrm{p}=0.003)$. Once established, however, lung injury was severe and the overall mortality rate was $75 \%$, regardless of therapy, with a 2 -week median time to death after the onset of IPS following HSCT (25). A systemic analysis of 20 studies (1090 patients) demonstrated an association between the incidence of IPS and the use of high-dose lung irradiation, high-dose cyclophosphamide, and the addition of busulfan $(24,26,27)$. Data generated from murine models propose that these conditioning agents produce lung epithelial injury followed by excessive requirement and activation of pulmonary macrophages and alloreactive T-lymphocytes (21). The other factors responsible for developing IPS following HSCT include an underlying diagnosis of acute leukemia or Myelodysplastic syndrome, older patient age, lower pretransplant performance status, total body irradiation (TBI), high-grade aGVHD, and positive donor cytomegalovirus serology (21). To date, the impact of the stem cell source (bone marrow vs. peripheral blood vs. umbilical cord blood) on the development of IPS has not been fully sought. Of note, despite the attempts to reduce the risk factors, the overall mortality due to IPS remains substantially high. The clinical manifestations of IPS include dyspnea, dry cough, hypoxemia, and radiographic opacities, which are similar to pneumonia of infectious etiology (20). Bronchoscopy with bronchoalveolar lavage (BAL) or transbronchial biopsy, if there is no contraindication, needs to be performed for the diagnosis of IPS cases. PFT and thorax CT are nonspecific. More than $90 \%$ of recipients with IPS have diffuse infiltrates on chest radiography as observed in the infections. Kantrow et al. (28) demonstrated the identification of IPS in $80 \%$ of patients by BAL, of whom $4 \%$ required lung biopsy and $16 \%$ were diagnosed at autopsy. Diffuse alveolar damage, organizing or acute pneumonia, and interstitial lymphocytic inflammation are observed in the lung biopsies of patients with suspected IPS.

The median time of onset of IPS is 21-65 days, ranging from 0 to 1653 days following allogeneic HSCT $(21,24,29)$. Historically, the clinical outcomes among HSCT recipients with IPS have been generally poor, with an estimated overall mortality 
rate of $74 \%$ (range, $60 \%-80 \%$ ) (7). The 1 -year OS is $<15 \%$ $(28,30)$. Most of the patients with IPS develop progressive respiratory failure requiring mechanical ventilation, in which the mortality rate exceeds $95 \%$ (28). Treating patients with IPS is still challenging since there are no data clarifying the type of the relevant therapy for HSCT recipients. Currently, the only accepted treatment option is supportive care (supplemental oxygen, diuretics) combined with broad-spectrum antimicrobial agents with or without intravenous high-dose glucocorticoids of $1 \mathrm{mg} / \mathrm{kg}$ or more (6). Although a small number of reports have shown limited responses to standard therapy, the mortality in IPS cases still remains unacceptably high (14). Advances in supportive care, including the early institution of continuous veno-venous hemofiltration, may help to improve survival in selected patients. Unfortunately, prospective studies addressing the treatment of patients with IPS, including the specific use of corticosteroids, do not exist in the literature (7). Of note, trials with larger sample sizes have demonstrated no benefit of glucocorticoids in the outcome of patients $(28,30)$. The mixed inflammatory alveolar infiltrates described in mice with IPS are associated with an increase in the levels of certain cytokines [e.g., interleukin-6, interleukin-8, tumor necrosis factor alpha (TNF $\alpha)$ ] in both lung tissue and BAL fluid $(31,32)$. Based on these results, sequential trials of the combination of a systemic corticosteroid with a TNF $\alpha$ inhibitor (etanercept or infliximab) have been conducted. Recently, a research group from the University of Michigan reported the outcomes of 15 patients with IPS who were treated with glucocorticoids and etanercept $(0.4 \mathrm{mg} / \mathrm{kg}$ and maximum $25 \mathrm{mg})$ twice weekly with a maximum of eight doses. In the evaluation of that report, $67 \%$ of the patients had a complete response within 3-18 days, and the survival rates at day 28 and day 56 (from the first etanercept dose) were $73 \%$ and $60 \%$, respectively (29). Based on these encouraging results, investigators from the University of Pennsylvania conducted a randomized placebo-controlled trial with single-agent corticosteroids or in combination with etanercept; favorable outcome was obtained in the combination group following the onset of IPS (at day $28: 88.2 \%$ vs. $36.4 \%$, $\mathrm{p}<0.001$, and at 2 years: $18 \%$ vs. $9.1 \%, \mathrm{p}<0.003$ ) (6). The Children's Oncology Group and the Pediatric Blood and Marrow Transplant Consortium recently completed a phase II, open label trial of etanercept along with glucocorticoids and reported similar response rates that approximate prior series in the preliminary analysis (6). With enormous progress in the understanding of the pathways involved in the development of IPS, treatment of IPS may lead into a new era. Ultimately, the low accrual rates point out the inherent difficulties in conducting definitive trials on HSCT patients with IPS.

\section{DIFFUSE ALVEOLAR HEMORRHAGE}

In 1989, Robbins et al. (33) defined a description of a subset of patients who have diffuse pulmonary infiltrates, fever, hypoxemia, thrombocytopenia, and renal failure occurring within the first few weeks after autologous HSCT for solid malignancy (33-38). The primary feature of this syndrome was progressive bloodier return of BAL fluid without frank hemoptysis (39). Most commonly, DAH occurs in the early period after HSCT and develops in 5\%-12\% of HSCT recipients with a median time to onset of 19 days (range, 5-34 days) in allogeneic recipients (21). However, a higher incidence of DAH has been reported in HSCT recipients with inherited metabolic storage disease, especially mucopolysaccharidosis (40). The pathogenesis of DAH after HSCT is not clearly understood. The presence of neutrophils in the BAL fluid of some HSCT recipients with DAH proposes an inflammatory process. The diagnosis of DAH is based on progressively hemorrhagic return on sequential BAL from at least three separate subsegmental bronchi and the presence of $>20 \%$ hemosiderin-laden macrophages in BAL fluid, which may require as long as 48-72 $\mathrm{h}$ to appear on cytological analysis in the absence of a respiratory tract infection $(7,41)$. Hemosiderin-laden macrophages are also observed in patients with thrombocytopenia or pulmonary hypertension (42). Risk factors for DAH after HSCT include age older than 40 years, TBI, HSCT for solid malignancies, and the presence of high fevers, severe mucositis, neutrophil engraftment, and renal failure $(33,43)$. To date, the effect of conditioning regimens or the stem cell source on the development of DAH remains to be elucidated. Common symptoms are dyspnea (92\%), fever (67\%), cough (56\%), and hemoptysis (15\%) (39). Most of the individuals with DAH need intensive care unit admission and mechanical ventilation. Patients with DAH typically have patchy or diffuse infiltrates that start centrally on thorax high-resolution computed tomography (HRCT). Surgical lung biopsies or postmortem examination in DAH shows the proliferative phase of diffuse alveolar damage (33-47). Prospective randomized trials regarding the treatment of DAH have not yet been conducted. Based on anecdotal reports and retrospective studies, systemic high-dose glucocorticoids (500$1000 \mathrm{mg} /$ day of methylprednisolone for 3-4 days followed by dose-tapering over 4 weeks) are usually administered to treat DAH $(48,49)$.

In 2006, Wanko et al. (50) determined that high-dose glucocorticoid therapy ( $>4 \mathrm{mg} / \mathrm{kg} /$ day of methylprednisolone equivalent) may have increased efficacy with decreased mortality rates ( $91 \%$ vs. $67 \%$ ) and the addition of aminocaproic acid may further improve the outcomes. In contrast to this report, Rathi et al. (51) from Duke University showed no significant differences in outcome with or without the addition 
of aminocaproic acid, regardless of methylprednisolone doses. Similarly, no significant response to corticosteroid treatment was noted in a small retrospective pediatric DAH trial (52). The reported mortality rates in HSCT recipients with DAH range from $70 \%$ to $100 \%(24,53)$. There is only one report from Mayo Clinic, which demonstrated a low mortality rate of $33 \%$ (7). It has to be mentioned that alveolar hemorrhage is a distinct entity with extremely poor outcomes following therapy with corticosteroids.

\section{PERDS (ENGRAFTMENT SYNDROME)}

PERDS occurs early in the post-transplant period. A study from Mayo Clinic first described the clinical entity comprising fever of $\geq 38.3^{\circ} \mathrm{C}$, radiographic diffuse pulmonary infiltrates, absence of cardiac insufficiency, hypoxemia, and an erythematous maculopapular rash (not attributable to drugs), with no identified infectious etiology (54). PERDS develops within 96 $\mathrm{h}$ of neutrophil recovery, with an incidence of 7\%-11\% (55). This syndrome is more common in autologous HSCT recipients (56-60). The pulmonary manifestations of PERDS are due to noncardiogenic diffuse capillary leak. Chest radiography and chest CT show bilateral ground-glass infiltration and hilar or peribronchial consolidation. Neutrophils may be observed in BAL fluid. The causes of this syndrome are still unclear, but the production of proinflammatory cytokines during engraftment is believed to play a regulatory role (61). Notably, the incidence and severity of this condition may be increased by the use of granulocyte-colony-stimulating factor (GCSF); therefore, discontinuation of GCSF is recommended for HSCT recipients with PERDS (62-67). A rapid response to corticosteroids has been postulated in patients with pulmonary involvement, but the mortality rate remains unacceptably high after progressing to respiratory failure $(54,56)$.

\section{DELAYED PULMONARY TOXICITY SYNDROME}

DPTS is defined by the presence of interstitial pneumonitis and fibrosis, which may delay for months to years (2). The incidence of DPTS is $29 \%-64 \%$ in autologous HSCT recipients who have received conditioning regimens containing cyclophosphamide, cisplatin, etoposide, and bischloroethylnitrosurea (BCNU) $(68,69)$. The median time of onset of DPTS is 45 days (range, 21-49 days) after HSCT (21).

Patients with DPTS present with fever, dyspnea, cough, and hypoxemia and have patchy or diffuse mixed reticular infiltrates on the chest radiograph (7). Lung biopsy demonstrates diffuse alveolar damage, interstitial pneumonitis, and thickening of the interstitium with early fibrosis (17). In a series of patients with breast cancer receiving high-dose cyclophosphamide, cisplatin, and $\mathrm{BCNU}$ followed by autologous $\mathrm{HSCT},>30 \%$ decline in diffusing gas transfer was observed in 15-18 weeks following the chemotherapy (68). In addition, 17\% improvement in diffusing capacity of carbon monoxide (DLCO) had been demonstrated among symptomatic patients treated with corticosteroids (prednisone $60 \mathrm{mg} /$ day for 2 weeks, followed by a 6 -week taper) (68). It has to be mentioned that there are no prospective and randomized trials to establish the efficacy of corticosteroid treatment in this setting. No deaths attributable to DPTS were reported. It is important to note that high incidence, low mortality, and good response to glucocorticoid therapy distinguish this process from IPS.

\section{BRONCHIOLITIS OBLITERANS SYNDROME}

BOS is the most common late noninfectious pulmonary complication following allogeneic HSCT. It was initially defined in the 1980s as a histologic entity of small airway inflammation with intraluminal fibrosis $(70,71)$. BOS is a clinical term described based on PFT abnormalities without histological confirmation (72). The incidence of BOS after allogeneic HSCT varies widely from $1.7 \%$ to $26 \%$, and, consequently, the nonuniform diagnostic criteria were used to define the condition (73). In 2005, the NIH Consensus Statement on the diagnosis and staging of cGVHD consisted of strict diagnostic criteria for BOS and subsequently recommended modifications that improved the identification of HSCT recipients with BOS (74). The development of BOS is closely associated with the presence of cGVHD. Other frequently observed risk factors for BOS include methotrexate use, serum immunoglobulin deficiency (especially immunoglobulins $\mathrm{G}$ and $\mathrm{A}$ ), prior occurrence of aGVHD, older recipient ( $>20$ years) and donor age, pretransplant low forced expiratory volume in $1 \mathrm{~s}$ (FEV1)/forced vital capacity $(\mathrm{FVC})$ ratio $(<0.7)$, and respiratory viral infections within the first 100 days after HSCT (72). In the multivariate analysis reported by the IBMTR (International Blood and Marrow Transplant Registry), busulfan-based conditioning regimen, peripheral blood stem cell transplantation, duration from the diagnosis of leukemia to HSCT (>14 months), female donor to male recipient, history of interstitial pneumonitis, and an event of moderate-to-severe aGVHD have been found as risk factors for BOS (75-78). The pathogenesis of BOS after HSCT has not been very well defined. Several hypotheses have been suggested; however, none of them have a satisfactory explanation for the BOS pathogenesis. The strong association between BOS and cGVHD proposes alloimmunological injury to host bronchiolar epithelial cells (75). Indeed, some investigators suggest that BOS is a manifestation of cGVHD. There are also alternative theories such as viral infections, recurrent aspiration due to GVHD-associated esophagitis, lung 
injury precipitated by the conditioning chemoradiotherapy, abnormal local defense mechanisms in the lung, and impaired mucociliary transport (79). In 2002, Hauber et al. (80) compared the results of BAL fluid analysis of 11 HSCT recipients with pulmonary complications (six had IPS and/or BOS) with those of 11 healthy volunteers. They found significantly higher levels of TNF $\alpha$ and interleukin-18 in the BAL fluid analysis of the patient cohort compared with those of the controls (80). The median onset time of BOS is approximately 1 year (range, 3 months to 10 years) $(81,82)$. In an IBMTR report, the median interval from transplant to diagnosis of BOS was found to be 431 days (range, 65-2444 days) (82). The common respiratory symptoms are dry cough $(60 \%-100 \%)$, progressive dyspnea (50\%-70\%), and wheezing $(40 \%)(83,84)$. Unlike BOOP, fever is rare in BOS. A total of $20 \%$ of patients remain asymptomatic despite having evidence of abnormal PFT findings (83). More than 33\% of recipients with cGVHD have evidence of airflow obstruction, and these patients should be followed up closely (75). Spirometry is the primary procedure used to diagnose and follow up HSCT recipients with BOS. PFT usually shows new-onset airflow obstruction with a decrease in FEV1 and FEV1/FVC ratio. Chest radiography is often normal or may represent hyperinflation (83). Expiratory air trapping, mosaic perfusion, bronchial dilatation, and bronchial wall thickening are generally observed on thorax HRCT (85). Bronchoscopy with BAL in HSCT recipients with BOS is nonspecific with the presence of neutrophilic and/or lymphocytic inflammation (86). BAL is primarily performed to rule out infectious etiologies. Transbronchial lung biopsy is generally not recommended because of the involvement of respiratory and membranous bronchioles in this condition. Surgical lung biopsy by video-assisted thoracoscopic surgery is required for histological confirmation. Lung biopsies reveal small airway involvement with fibrogenic deposition (79). A recent study established that histological BOS diagnosis was not superior to clinical diagnosis depending on clinical symptoms, PFT abnormalities, and radiographic signs beyond the time of biopsy (87). The following diagnostic criteria for BOS were recently reported by an NIH workshop: (i) FEV1/ FVC $<0.7$ and FEV $1<75 \%$ of predicted value; (ii) HRCT of chest (with inspiratory and expiratory views) showing spaces of air trapping or small airway thickening or bronchiectasis, residual volume of PFT $>120 \%$ of predicted value, or histological confirmation of constrictive bronchiolitis; and (iii) absence of infection in the respiratory tract documented by clinical symptoms, radiological procedures, or microbiological cultures (88). Another significant determination of the NIH Consensus Development Project is to form a scoring system of pulmonary cGVHD based on symptoms and PFT findings.
There are no prospective, randomized trials addressing the standard treatment of BOS. Based on small, uncontrolled trials and expert opinions, high-dose systemic corticosteroids and augmented immunosuppression are administered for treatment $(89,90)$. Prednisolone $1-1.5 \mathrm{mg} / \mathrm{kg} /$ day (up to $100 \mathrm{mg} /$ day) for 2-6 weeks is suggested, and if the respiratory status remains stable, the dose is tapered every 2 weeks for 6-12 months. Immunosuppression with cyclosporine $\mathrm{A}$ or azathioprine is initiated when there is no response to corticosteroid therapy within 1 month (91). In addition, azathioprine doses are 2-3 $\mathrm{mg} / \mathrm{kg}$ /day (maximum $200 \mathrm{mg} /$ day), and cyclosporine A dose should be adjusted according to serum levels for 3-12 months. Extracorporeal photodynamic (ECP) has been proven to be an effective treatment option for cGVHD. The published reports on the effectiveness of ECP for HSCT recipients with BOS are even less compelling. The Regensburg conference recommended ECP as a frontline therapy choice for BOS (79). However, there are only three reports encouraging the benefits of this therapy in pulmonary manifestations of cGVHD. Lucid et al. (92) conducted the only study using ECP in patients with BOS following HSCT in 2011. This retrospective analysis reported some degree of stabilization in FEV1 in six of nine patients with BOS, comparing FEV1 values prior to and during ECP treatment (92).

BOS following HSCT is a progressive disorder that may lead to irreversible airflow obstruction. Intensive treatments resulting in an improvement of pulmonary functions are noted in only $8 \%$ and $20 \%$ of cases (7). The goal of the treatment of BOS must be stabilization and prevention of further drops in FEV1. The published mortality rates vary from $14 \%$ to $100 \%$ (mean, $61 \%)$ (7). The major causes of death are progressive respiratory failure and opportunistic lung infections. Rapid deterioration of FEV1 (more than $10 \%$ per year), which is refractory to firstline therapy, recipient age $>60$ years, progressive cGVHD, and prior respiratory viral infections are associated with a worse prognosis (72). With clarification of the specific pathways in BOS, anti-inflammatory and immunomodulatory therapies targeting these pathways may be developed for the future management of HSCT recipients with BOS.

\section{BRONCHIOLITIS OBLITERANS ORGANIZING PNEUMONIA}

BOOP was first described in the early 1990s and presents more like pneumonia than airway disease within the first 2-6 months following HSCT (93). It is characterized by an extensive infiltration of granulation tissue within alveolar ducts and alveoli, consisting of fibroblasts and a matrix of loose connective tissue. In contrast to BOS, BOOP is exclusively an alveolar disorder; there is no prominent bronchiolar damage (94). 
Recently, to avoid confusion with BOS terminology, BOOP has been renamed as cryptogenic organizing pneumonia (95). Even though the pathogenesis of BOOP after HSCT is not clearly understood, published reports have postulated that alloimmune injury is the primary triggering factor for its development. In murine models, BOOP occurs after retrovirus infections in which $\mathrm{T}$ cells and $\mathrm{T}$ helper 1-derived cytokines, including interferon- $\alpha$, play an important role in the development of this process (96). Although a consensus on the identification criteria is lacking, the incidence of BOOP is $0.9 \%-10.3 \%$ (61). Freudenberger et al. (97) reviewed the data of 5.340 patients who underwent allogeneic HSCT, and 49 cases $(0.9 \%)$ of histologic BOOP were diagnosed. A report from Mayo Clinic analyzed the incidence of BOOP among HSCT recipients and reported that $1.6 \%$ and $10.3 \%$ of patients who underwent HSCT from matched sibling donors and unrelated donors respectively developed BOOP (98). The risk factors for BOOP include HLA disparity, HSCT from a female donor to a male recipient, and the use of peripheral blood as a stem cell source. Notably, an association between GVHD and the subsequent occurrence of BOOP has been reported (72). In the literature, the development of BOOP has also been defined as somehow a rejection of the lung by the donor's stem cells (7). BOOP usually presents with fever, nonproductive cough, and dyspnea. A mild-to-moderate restrictive defect (FVC $<80 \%$, FEV1/FVC $\geq 80 \%$ ), commonly decreased DLCO, and in contrast to BOS, normal expiratory flow are observed in the PFT (6). The radiologic findings in BOOP include peripheral patchy air space consolidation termed as "fluffy," ground-glass and nodular opacities. Lee et al. (99) reported the radiographic patterns in 43 HSCT recipients with biopsy-proven BOOP. Consolidation was the most common pattern in $79 \%$ of cases; ground-glass attenuation and nodular opacities were noted in $60 \%$ and $30 \%$, respectively (99). Bronchoscopy and BAL fluid are useful to exclude pulmonary infection and for the demonstration of BOOP. Lymphocytosis with a decreased $\mathrm{CD} 4+/ \mathrm{CD} 8+$ ratio was revealed in the cytological analysis of BAL fluid (72). Transbronchial or surgical lung biopsy procedures are considered as the gold standard for diagnosis. The histologic hallmark of BOOP is the presence of patchy intraluminal fibrosis resembling granulation tissue in distal airways extending to the alveolar ducts and peribronchial alveolar spaces (100). Although there is no standard treatment for HSCT recipients with BOOP, corticosteroid is the mainstay of treatment. Based on limited retrospective reports, it has been shown that approximately $80 \%$ of patients respond favorably to systemic corticosteroid therapy (7). The initial dose of corticosteroid treatment is prednisone $0.75-1.5 \mathrm{mg} / \mathrm{kg} /$ day for 1-3 months and $40 \mathrm{mg}$ for 3 months, followed by $10-20 \mathrm{mg}$ for a total of 1 year. Reported relapse rate varies from $9 \%$ to $58 \%$; therefore, prolonged treatment courses have been recommended (101). Recently, Radzikowska et al. (102) compared the outcome of corticosteroid and clarithromycin treatment in patients with biopsy-proven BOOP. Complete remission was achieved in $88 \%$ of patients treated with clarithromycin and in all patients treated with corticosteroids. Of note, recurrence was observed more frequently in the corticosteroid group $(54.5 \%$ vs. $10 \%$; $\mathrm{p}<0.0001$ ) (102). Freudenberger et al. (97) reported that BOOP following HSCT resolved in $57 \%$ of patients and remained stable in $21 \%$ of cases. Progression of disorder was observed in $11(22 \%)$ patients despite corticosteroid therapy, with initial doses ranging from $1 \mathrm{mg} / \mathrm{kg} /$ day to $2 \mathrm{~g}$ /day. Of the 11 patients, $8(73 \%)$ died of respiratory failure attributed to BOOP (97). It is important to note that more clinical trials should be conducted to understand the dose and duration of corticosteroid therapy.

\section{PULMONARY VENO-OCCLUSIVE DISEASE}

Pulmonary veno-occlusive disease (PVOD) occurs rarely and has a late onset (after the first 100 days) after allogeneic HSCT (39). PVOD is identified by intimal proliferation and fibrosis of the pulmonary venules and small veins that result in progressive vascular obstruction with high pulmonary and capillary pressure (103). Patients with PVOD present with dyspnea and fatigue within post-transplant 3-4 months. PFT shows a mild restrictive ventilation defect and a decreased DLCO. Chest radiographs and $\mathrm{CT}$ reveal a pleural effusion, diffuse or mosaic ground-glass attenuation, and nodular opacities. CT pulmonary angiography excludes the evidence of thrombi as a cause of pulmonary hypertension. The diagnosis of PVOD cannot be made unless right-sided heart catheterization demonstrates findings with elevated pulmonary artery pressure $(\geq 25 \mathrm{mmHg})$ and a normal pulmonary artery wedge pressure $(<15 \mathrm{mmHg})$. The triad of pulmonary artery hypertension, radiographic signs of pulmonary edema, and a normal pulmonary artery occlusion pressure strongly proposes the diagnosis of PVOD (103).

Treatment-associated risks such as pulmonary edema and respiratory failure are higher with vasodilators, which must be initiated under close observation. Hackman et al. (104) reported the efficacy of high-dose corticosteroid therapy (methylprednisolone $2.0 \mathrm{mg} / \mathrm{kg} /$ day) in a series of two patients with PVOD.

\section{PULMONARY CYTOLYTIC THROMBI}

Pulmonary cytolytic thrombi (PCT) is an unusual pulmonary complication of HSCT (105). The etiology of new-onset PCT after HSCT is unknown. The median time of onset of PCT is 72 days (range, 8-343 days). PCT occurs particularly in children with GVHD and consequently has been believed to be a 
manifestation of acute and chronic GVHD (105). It should be suspected in HSCT recipients with fever and numerous peripheral pulmonary nodules on chest $\mathrm{CT}$. The prognostic procedure of choice is surgical lung biopsy showing necrotic, basophilic thromboembolism with entrapped monocytes (106). The clinical presentations improve within 1-2 weeks, and radiographic findings disappear over weeks to months. There is no proven therapy for PCT. Recently, investigators from the University of Minnesota reported the outcome of 14 HSCT recipients with PCT who had received $1-2 \mathrm{mg} / \mathrm{kg} /$ day of prednisone (or equivalent methylprednisolone dosing) until the resolution of pulmonary symptoms (typically 1-2 weeks, followed by a rapid taper over 2-4 weeks) with a 3-year OS of 71\% (105).

Pulmonary complications are frequently observed after HSCT and remain a leading cause of morbidity and mortality. Effective prophylaxis of infections with antibiotics is changing the scene of pulmonary complications from infectious to noninfectious etiologies. The pathogenesis and diagnostic criteria of these complications have not yet been clearly defined. It is important to note that treatment of HSCT recipients with noninfectious pulmonary complications is still challenging, and the current treatment armamentarium and strategies are not adequate. Therefore, further trials are needed for a better description of the pathogenesis and the complete diagnostic criteria as well as for the development of effective therapeutic approaches for the management of noninfectious pulmonary complications of HSCT recipients.

Financial Disclosure: No financial disclosure was declared by the authors.

Conflict of Interest: No conflict of interest was declared by the authors.

\section{REFERENCES}

1. Demirer T, Peterson FB, Bensinger WI, Appelbaum FR, Fefer A, Rowley S, et al. Autologous transplantation with peripheral blood stem cells collected after granulocyte colony-stimulating factor in patients with acute myelogenous leukemia. Bone Marrow Transplantat 1996;18:29-34.

2. Peccatori J, Barkholt L, Demirer T, Sormani MP, Bruzzi P, Ciceri F, et al. Prognostic factors for survival in patients with advanced renal cell carcinoma undergoing nonmyeloablative allogeneic stem cell transplantation. Cancer 2005;104:2099-103.

3. Demirer T, Celebi H, Arat M, Ustün C, Demirer S, Dilek I, et al. Autoimmune thrombocytopenia in a patient with small cell lung cancer developing after chemotherapy and resolving following autologous peripheral blood stem cell transplantation. Bone Marrow Transplant 1999;24:335-7.

4. De Giorgi U, Rosti G, Slavin S, Yaniv I, Harousseau JL, Ladenstein R, et al. Salvage high-dose chemotherapy for children with extragonadal germ-cell tumours. $\mathrm{Br} \mathrm{J}$ Cancer 2005;93:412-7.

5. Pedrazzoli P, Ferrante P, Kulekci A, Schiavo R, De Giorgi U, Carminati O, et al. Autologous hematopoietic stem cell transplantation for breast cancer in Europe: critical evaluation of data from the European Group for Blood and Marrow Transplantation (EBMT) Registry 1990-1999. Bone Marrow Transplant 2003;32:489-94.

6. Yanik G, Kitko C. Management of noninfectious lung injury following hematopoietic cell transplantation. Curr Opin Oncol 2013;25:187-94.

7. Afessa B, Litzow MR, Tefferi A. Bronchiolitis obliterans and other late onset noninfectious pulmonary complications in hematopoietic stem cell transplantation. Bone Marrow Transplant 2001;28:425-34.
8. Demirer T, Buckner CD, Appelbaum FR, Bensinger WI, Sanders J, Lambert K, et al Busulfan, cyclophosphamide and fractionated total body irradiation for autologous or syngeneic marrow transplantation for acute and chronic myelogenous leukemia: Phase I dose escalation of busulfan based on targeted plasma levels. Bone Marrow Transplant 1996;17:491-5.

9. Demirer T, Buckner CD, Appelbaum FR, Lambert K, Bensinger WI, Clift R, et al. Busulfan, cyclophosphamide and fractionated total body irradiation for allogeneic marrow transplantation in advanced acute and chronic myelogenous leukemia: Phase I dose escalation of busulfan based on targeted plasma levels. Bone Marrow Transplant 1996;17:341-6.

10. Pedrazzoli P, Ledermann JA, Lotz JP, Leyvraz S, Aglietta M, Rosti G, et al. High dose chemotherapy with autologous hematopoietic stem cell support for solid tumors other than breast cancer in adults. Ann Oncol 2006;17:1479-88.

11. Berry DA, Ueno NT, Johnson MM, Lei X, Caputo J, Smith DA, et al. HighDose Chemotherapy with Autologous Hematopoietic Stem-Cell Transplantation in Metastatic Breast Cancer: Overview of Six Randomized Trials. J Clin Oncol 2011;29:3224-31.

12. Gratwohl A, Baldomero H, Demirer T, Rosti G, Dini G, Ladenstein R, et al Hematopoetic stem cell transplantation for solid tumors in Europe. Ann Oncol 2004; $15: 653-60$

13. Cerveri I, Zoia MC, Fulgoni P, Corsico A, Casali L, Tinelli C, et al. Late pulmonary sequelae after childhood bone marrow transplantation. Thorax 1999;54:131-5.

14. Griese M, Rampf U, Hofmann D, Führer M, Reinhardt D, Bender-Götze C. Pulmonary complications after bone marrow transplantation in children: twenty-four years of experience in a single pediatric center. Pediatr Pulmonol 2000;30:393-401.

15. Milburn HJ, Prentice HG, du Bois RM. Can lung function measurements be used to predict which patients will be at risk of developing interstitial pneumonitis after bone marrow transplantation? Thorax 1992;47:421-5.

16. Crawford SW, Fisher L. Predictive value of pulmonary function tests before marrow transplantation. Chest 1992;101:1257-64.

17. Cooke KR. Acute lung injury after allogeneic stem cell transplantation: from the clinic, to the bench and back again. Pediatr Transplant 2005;9(Suppl 7):25-36.

18. Yousem SA. The histological spectrum of pulmonary graft-versus-host disease in bone marrow transplant recipients. Hum Pathol 1995;26:668-75.

19. Chi AK, Soubani AO, White AC, Miller KB. An update on pulmonary complications of hematopoietic stem cell transplantation. Chest 2013;144:1913-22.

20. Clark JG, Hansen JA, Hertz MI, Parkman R, Jensen L, Peavy HH. NHLBI workshop summary. Idiopathic pneumonia syndrome after bone marrow transplantation. Am Rev Respir Dis 1993;147:1601-6.

21. Panoskaltsis-Mortari A, Griese M, Madtes DK, Belperio JA, Haddad IY, Folz RJ, et al. An official American Thoracic Society research statement: noninfectious lung injury after hematopoietic stem cell transplantation: idiopathic pneumonia syndrome. Am J Respir Crit Care Med 2011;183:1262-79.

22. Keates-Baleeiro J, Moore P, Koyama T, Manes B, Calder C, Frangoul H. Incidence and outcome of idiopathic pneumonia syndrome in pediatric stem cell transplant recipients. Bone Marrow Transplant 2006;38:285-9.

23. Patriarca F, Skert C, Bonifazi F, Sperotto A, Fili C, Stanzani M, et al. Effect on survival of the development of late-onset non-infectious pulmonary complications after stem cell transplantation. Haematologica 2006;91:1268-72.

24. Fukuda T, Hackman RC, Guthrie KA, Sandmaier BM, Boeckh M, Maris MB, et al. Risks and outcomes of idiopathic pneumonia syndrome after nonmyeloablative and conventional conditioning regimens for allogeneic hematopoietic stem cell transplantation. Blood 2003;102:2777-85.

25. Sakaguchi H, Takahashi Y, Watanabe N, Doisaki S, Muramatsu H, Hama A, et al Incidence, clinical features, and risk factors of idiopathic pneumonia syndrome following hematopoietic stem cell transplantation in children. Pediatr Blood Cancer 2012;58:780-4.

26. Brunvand MW, Bensinger WI, Soll E, Weaver CH, Rowley SD, Appelbaum FR, et al. High-dose fractionated total-body irradiation, etoposide and cyclophosphamide for treatment of malignant lymphoma: Comparison of autologous bone marrow and peripheral blood stem cells. Bone Marrow Transplant 1996;18:131-41.

27. Atilla E, Atilla PA, Toprak SK, Demirer T. A Review of Late Complications of Allogeneic Hematopoietic Stem Cell Transplantations. Clin Transplant 2017;31.

28. Kantrow SP, Hackman RC, Boeckh M, Myerson D, Crawford SW. Idiopathic pneumonia syndrome: changing spectrum of lung injury after marrow transplantation. Transplantation 1997;63:1079-86. 
29. Yanik GA, Ho VT, Levine JE, White ES, Braun T, Antin JH, et al. The impact of soluble tumor necrosis factor receptor etanercept on the treatment of idiopathic pneumonia syndrome after allogeneic hematopoietic stem cell transplantation. Blood 2008;112:3073-81.

30. Crawford SW, Hackman RC. Clinical course of idiopathic pneumonia after bone marrow transplantation. Am Rev Respir Dis 1993;147:1393-400.

31. Cooke KR, Hill GR, Gerbitz A, Kobzik L, Martin TR, Crawford JM, et al. Tumor necrosis factor-alpha neutralization reduces lung injury after experimental allogeneic bone marrow transplantation. Transplantation 2000;70:272-9.

32. Cooke KR, Kobzik L, Martin TR, Brewer J, Delmonte J Jr, Crawford JM, et al. An experimental model of idiopathic pneumonia syndrome after bone marrow transplantation: I. The roles of minor H antigens and endotoxin. Blood 1996;88:3230-9.

33. Robbins RA, Linder J, Stahl MG, Thompson AB, Haire W, Kessinger A, et al. Diffuse alveolar hemorrhage in autologous bone marrow transplant recipients. Am J Med 1989;87:511-8.

34. Sahin U, Toprak SK, Atilla PA, Atilla E, Demirer T. An Overview of Infectious Complications after Allogeneic Hematopoietic Stem Cell Transplantation. J Infect Chemother 2016;22:505-14.

35. Sahin U, Ataca Atilla P, Atilla E, Toprak SK, Demirer T. An Overview of Hematopoietic Stem Cell Transplantation Related Thrombotic Complications. Crit Rev Oncol Hematol 2016;107:149-55.

36. Atilla E, Ataca Atilla P, Demirer T. A Review of Myeloablative vs Reduced Intensity/Non-Myeloablative Regimens in Allogeneic Hematopoietic Stem Cell Transplantations. Balkan Med J 2017;34:1-9.

37. Atilla E, Atilla PA, Demirer T. Current Treatment Strategies in Relapsed/Refractory Mantle Cell Lymphoma: Where are we now? Int J Hematol 2017;105:257-64.

38. Atilla E, Atilla PA, Bozdağ SC, Demirer T. A Review of Infectious Complications After Haploidentical Hematopoietic Stem Cell Transplantations. Infection 2017;45:403-11.

39. Watkins TR, Chien JW, Crawford SW. Graft versus host-associated pulmonary disease and other idiopathic pulmonary complications after hematopoietic stem cell transplant. Semin Respir Crit Care Med 2005;26:482-9.

40. Kharbanda S, Panoskaltsis-Mortari A, Haddad IY, Blazar BR, Orchard PJ, Cornfield $\mathrm{DN}$, et al. Inflammatory cytokines and the development of pulmonary complications after allogeneic hematopoietic cell transplantation in patients with inherited metabolic storage disorders. Biol Blood Marrow Transplant 2006;12:430-7.

41. Afessa B, Tefferi A, Litzow MR, Krowka MJ, Wylam ME, Peters SG. Diffuse alveolar hemorrhage in hematopoietic stem cell transplant recipients. Am J Respir Crit Care Med 2002;166:641-5.

42. Salih ZN, Akhter A, Akhter J. Specificity and sensitivity of hemosiderin-laden macrophages in routine bronchoalveolar lavage in children. Arch Pathol Lab Med 2006;130:1684-6.

43. Kröger N, Damon L, Zander AR, Wandt H, Derigs G, Ferrante P, et al. Secondary acute leukemia following mitoxantrone-based high-dose chemotherapy for primary breast cancer patients. Bone Marrow Transplant 2003;32:1153-7.

44. Demirer T, Gooley T, Buckner CD, Petersen FB, Lilleby K, Rowley S, et al. Influence of total nucleated cell dose from marrow harvests on outcome in patients with acute myelogenous leukemia undergoing autologous transplantation. Bone Marrow Transplant 1995;15:907-13.

45. Bensinger WI, Demirer T, Buckner CD, Appelbaum FR, Storb R, Lilleby K, Weiden $\mathrm{P}$, et al. Syngeneic marrow transplantation in patients with multiple myeloma. Bone Marrow Transplant 1996;18:527-31.

46. De Giorgi U, Demirer T, Wandt H, Taverna C, Siegert W, Bornhauser M, et al. Second-line high-dose chemotherapy in patients with mediastinal and retroperitoneal primary non-seminomatous germ cell tumors: the EBMT experience. Ann Oncol 2005;16:146-51.

47. Agustí C, Ramirez J, Picado C, Xaubet A, Carreras E, Ballester E, et al. Diffuse alveolar hemorrhage in allogeneic bone marrow transplantation. A postmortem study. Am J Respir Crit Care Med 1995;151:1006-10.

48. Metcalf JP, Rennard SI, Reed EC, Haire WD, Sisson JH, Walter T, et al. Corticosteroids as adjunctive therapy for diffuse alveolar hemorrhage associated with bone marrow transplantation. University of Nebraska Medical Center Bone Marrow Transplant Group. Am J Med 1994;96:327-34.

49. Raptis A, Mavroudis D, Suffredini A, Molldrem J, Rhee FV, Childs R, et al. Highdose corticosteroid therapy for diffuse alveolar hemorrhage in allogeneic bone marrow stem cell transplant recipients. Bone Marrow Transplant 1999;24:879-83.
50. Wanko SO, Broadwater G, Folz RJ, Chao NJ. Diffuse alveolar hemorrhage: retrospective review of clinical outcome in allogeneic transplant recipients treated with aminocaproic acid. Biol Blood Marrow Transplant 2006;12:949-53.

51. Rathi NK, Tanner AR, Dinh A, Dong W, Feng L, Ensor J, et al. Low-, medium- and high-dose steroids with or without aminocaproic acid in adult hematopoietic SCT patients with diffuse alveolar hemorrhage. Bone Marrow Transplant 2015;50:420-6.

52. Heggen J, West C, Olson E, Olson T, Teague G, Fortenberry J, et al. Diffuse alveolar hemorrhage in pediatric hematopoietic cell transplant patients. Pediatrics 2002;109:965-71.

53. Witte RJ, Gurney JW, Robbins RA, Linder J, Rennard SI, Arneson M, et al. Diffuse pulmonary alveolar hemorrhage after bone marrow transplantation: radiographic findings in 39 patients. AJR Am J Roentgenol 1991;157:461-4.

54. Capizzi SA, Kumar S, Huneke NE, Gertz MA, Inwards DJ, Litzow MR, et al. Periengraftment respiratory distress syndrome during autologous hematopoietic stem cell transplantation. Bone Marrow Transplant 2001;27:1299-303.

55. Maiolino A, Biasoli I, Lima J, Portugal AC, Pulcheri W, Nucci M. Engraftment syndrome following autologous hematopoietic stem cell transplantation: definition of diagnostic criteria. Bone Marrow Transplant 2003;31:393-7.

56. Spitzer TR. Engraftment syndrome following hematopoietic stem cell transplantation. Bone Marrow Transplant 2001;27:893-8.

57. Demirer T, Buckner CD, Appelbaum FR, Clift R, Storb R, Myerson D, et al. Highdose busulfan and cyclophosphamide followed by autologous transplantation in patients with advanced breast cancer. Bone Marrow Transplant 1996;17:769-74.

58. Holmberg LA, Demirer T, Rowley S, Buckner CD, Goodman G, Maziarz R, et al. High-dose busulfan, melphalan and thiotepa followed by autologous peripheral blood stem cell (PBSC) rescue in patients with advanced stage III-IV ovarian cancer. Bone Marrow Transplant 1998;22:651-9.

59. Demirer T, Buckner CD, Appelbaum FR, Petersen FB, Rowley S, Weaver CH, et al. Rapid engraftment after autologous transplantation utilizing marrow and recombinant granulocyte-colony stimulating factor mobilized peripheral blood stem cells in patients with acute myelogenous leukemia. Bone marrow Transplant 1995;15:915-22.

60. Rosti G, De Giorgi U, Wandt H, Lioure B, Leyvraz S, Kolbe K, et al. First-line highdose chemotherapy for patients with poor prognosis extragonadal germ cell tumors. The experience of the European Bone Marrow Transplantation (EBMT) Solid Tumors Working party. Bone Marrow Transplant 2004;34:1033-7.

61. Diab M, ZazaDitYafawi J, Soubani AO. Major Pulmonary Complications After Hematopoietic Stem Cell Transplant. Exp Clin Transplant 2016;14:259-70.

62. Marín D, Berrade J, Ferra C, Mateu A, Berlanga J, Salar A, et al. Engraftment syndrome and survival after respiratory failure post-bone marrow transplantation. Intensive Care Med 1998:24:732-5.

63. Lee CK, Gingrich RD, Hohl RJ, Ajram KA. Engraftment syndrome in autologous bone marrow and peripheral stem cell transplantation. Bone Marrow Transplant 1995; 16:175-82.

64. Demirer T, Ilhan O, Ayli M, Arat M, Dagli M, Ozcan M, et al. Monitoring of peripheral blood CD34+ cell counts on the first day of apheresis is highly predictive for efficient CD34+ cell yield. Ther Apher 2002;6:384-9.

65. Bakanay ŞM, Demirer T. Novel agents and approaches fors tem cell mobilization in normal donors and patients. Bone Marrow Transplant 2012;47:1154-63.

66. Demirer T, Ilhan O, Arat M, Genç Y, Ozcan M, Dalva K, et al. CD41+ and CD42+ hematopoietic progenitor cells predict platelet engraftment after allogeneic peripheral blood stem cell transplantation. J Clin Apher 2001;16:67-73.

67. Ataca Atilla P, Bakanay Ozturk SM, Demirer T. How to manage poor mobilizers for High Dose Chemotherapy and Autologous Stem Cell Transplantation? Transfus Apher Sci 2017;56:190-8.

68. Wilczynski SW, Erasmus JJ, Petros WP, Vredenburgh JJ, Folz RJ. Delayed pulmonary toxicity syndrome following high-dose chemotherapy and bone marrow transplantation for breast cancer. Am J Respir Crit Care Med 1998;157:565-73.

69. Bhalla KS, Wilczynski SW, Abushamaa AM, Petros WP, McDonald CS, Loftis JS, et al. Pulmonary toxicity of induction chemotherapy prior to standard or high-dose chemotherapy with autologous hematopoietic support. Am J Respir Crit Care Med 2000;161:17-25.

70. Holland HK, Wingard JR, Beschorner WE, Saral R, Santos GW. Bronchiolitis obliterans in bone marrow transplantation and its relationship to chronic graft-v-host disease and low serum IgG. Blood 1988;72:621-7. 
71. Crawford SW, Pepe M, Lin D, Benedetti F, Deeg, HJ. Abnormalities of pulmonary function tests after marrow transplantation predict nonrelapse mortality. Am J Respir Crit Care Med 1995;152:690-5.

72. Yoshihara S, Yanik G, Cooke KR, Mineishi S. Bronchiolitis obliterans syndrome (BOS), bronchiolitis obliterans organizing pneumonia (BOOP), and other late-onset noninfectious pulmonary complications following allogeneic hematopoietic stem cell transplantation. Biol Blood Marrow Transplant 2007;13:749-59.

73. Clark JG, Schwartz DA, Flournoy N, Sullivan KM, Crawford SW, Thomas ED. Risk factors for airflow obstruction in recipients of bone marrow transplants. Ann Intern Med 1987;107:648-56.

74. Martin PJ, Weisdorf D, Przepiorka D, Hirschfeld S, Farrell A, Rizzo JD, et al. National Institutes of Health Consensus Development Project on Criteria for Clinical Trials in Chronic Graft-versus-Host Disease: VI. Design of Clinical Trials Working Group report. Biol Blood Marrow Transplant 2006;12:491-505.

75. Chien JW, Martin PJ, Gooley TA, Flowers ME, Heckbert SR, Nichols WG, et al. Airflow obstruction after myeloablative allogeneic hematopoietic stem cell transplantation. Am J Respir Crit Care Med 2003;168:208-14.

76. Ueno NT, Rizzo JD, Demirer T, Cheng YC, Hegenbart U, Zhang MJ, et al. Allogeneic hematopoietic cell transplantation for metastatic breast cancer. Bone Marrow Transplant 2008;41:537-45.

77. Aglietta M, Barkholt L, Schianca FC, Caravelli D, Omazic B, Minotto C, et al. Reduced Intensity Allogeneic Hematopoietic Stem Cell Transplantation in Metastatic Colorectal Cancer as a Novel Adoptive Cell Therapy Approach. The European Group for Blood and Marrow Transplantation Experience. Biol Blood Marrow Transplant 2009;15:326-35.

78. Demirer T, Weaver CH, Buckner CD, Petersen FB, Bensinger WI, Sanders J, et al. High-dose cyclophosphamide, carmustine, and etoposide followed by allogeneic bone marrow transplantation in patients with lymphoid malignancies who had received prior dose-limiting radiation therapy. J Clin Oncol 1995;13:596-602.

79. Pandya CM, Soubani AO. Bronchiolitis obliterans following hematopoietic stem cell transplantation: a clinical update. Clin Transplant 2010;24:291-306.

80. Hauber HP, Mikkilä A, Erich JM, Kröger N, Meyer A, Schoder V, et al. TNF $\alpha$, interleukin-10 and interleukin-18 expression in cells of the bronchoalveolar lavage in patients with pulmonary complications following bone marrow or peripheral stem cell transplantation: a preliminary study. Bone Marrow Transplant 2002;30:485-90.

81. Dudek AZ, Mahaseth H, DeFor TE, Weisdorf DJ. Bronchiolitis obliterans in chronic graft-versus-host disease: analysis of risk factors and treatment outcomes. Biol Blood Marrow Transplant 2003;9:657-66.

82. Santo Tomas LH, Loberiza FR Jr, Klein JP, Layde PM, Lipchik RJ, Rizzo JD, et al. Risk factors for bronchiolitis obliterans in allogeneic hematopoietic stem-cell transplantation for leukemia. Chest 2005;128:153-61.

83. Clark JG, Crawford SW, Madtes DK, Sullivan KM. Obstructive lung disease after allogeneic marrow transplantation. Clinical presentation and course. Ann Intern Med 1989;111:368-76.

84. Chan CK, Hyland RH, Hutcheon MA, Minden MD, Alexander MA, Kossakowska AE, et al. Small-airways disease in recipients of allogeneic bone marrow transplants. An analysis of 11 cases and a review of the literature. Medicine (Baltimore) 1987;66:327-40.

85. Schultz KR, Green GJ, Wensley D, Sargent MA, Magee JF, Spinelli JJ, et al. Obstructive lung disease in children after allogeneic bone marrow transplantation. Blood 1994;84:3212-20.

86. St John RC, Gadek JE, Tutschka PJ, Kapoor N, Dorinsky PM. Analysis of airflow obstruction by bronchoalveolar lavage following bone marrow transplantation. Implications for pathogenesis and treatment. Chest 1990;98:600-7.

87. Uhlving HH, Andersen CB, Christensen IJ, Gormsen M, Pedersen KD, Buchvald F, et al. Biopsy-verified bronchiolitis obliterans and other noninfectious lung pathologies after allogeneic hematopoietic stem cell transplantation. Biol Blood Marrow Transplant 2015;21:531-8.
88. Filipovich AH, Weisdorf D, Pavletic S, Socie G, Wingard JR, Lee SJ, et al. National Institutes of Health consensus development project on criteria for clinical trials in chronic graft-versus-host disease: I. Diagnosis and staging working group report. Biol Blood Marrow Transplant 2005;11:945-56.

89. Ratjen F, Rjabko O, Kremens B. High-dose corticosteroid therapy for bronchiolitis obliterans after bone marrow transplantation in children. Bone Marrow Transplant 2005;36:135-8.

90. Ishii T, Manabe A, Ebihara Y, Ueda T, Yoshino H, Mitsui T, et al. Improvement in bronchiolitis obliterans organizing pneumonia in a child after allogeneic bone marrow transplantation by a combination of oral prednisolone and low dose erythromycin. Bone Marrow Transplant 2000;26:907-10.

91. Crawford SW, Clark JG. Bronchiolitis associated with bone marrow transplantation. Clin Chest Med 1993;14:741-9.

92. Lucid CE, Savani BN, Engelhardt BG, Shah P, Clifton C, Greenhut SL, et al Extracorporeal photopheresis in patients with refractory bronchiolitis obliterans developing after allo-SCT. Bone Marrow Transplant 2011;46:426-9.

93. Thirman MJ, Devine SM, O'Toole, K, Cizek G, Jessurun J, Hertz M, et al. Bronchiolitis obliterans organizing pneumonia as a complication of allogeneic bone marrow transplantation. Bone Marrow Transplant 1992;10:307-11.

94. Cordier Bronchiolitis obliterans organizing pneumonia. Sem Resp Crit Care M 2000;21:135-46

95. American Thoracic Society; European Respiratory Society. American Thoracic Society/European Respiratory Society International Multidisciplinary Consensus Classification of the Idiopathic Interstitial Pneumonias. This joint statement of the American Thoracic Society (ATS), and the European Respiratory Society (ERS) was adopted by the ATS board of directors, June 2001 and by the ERS Executive Committee, June 2001. Am J Respir Crit Care Med 2002;165:277-304.

96. Majeski EI, Paintlia MK, Lopez AD, Harley RA, London SD, London L. Respiratory reovirus $1 / \mathrm{L}$ induction of intraluminal fibrosis, a model of bronchiolitis obliterans organizing pneumonia, is dependent on T lymphocytes. Am J Pathol 2003;163:146779.

97. Freudenberger TD, Madtes DK, Curtis JR, Cummings P, Storer BE, Hackman RC. Association between acute and chronic graft-versus-host disease and bronchiolitis obliterans organizing pneumonia in recipients of hematopoietic stem cell transplants. Blood 2003;102:3822-8.

98. Palmas A, Tefferi A, Myers JL, Scott JP, Swensen SJ, Chen MG, et al. Late-onset noninfectious pulmonary complications after allogeneic bone marrow transplantation. Br J Haematol 1998;100:680-7.

99. Lee KS, Kullnig P, Hartman TE, Müller NL. Cryptogenic organizing pneumonia: CT findings in 43 patients. AJR Am J Roentgenol 1994;162:543-6.

100. Myers JL, Colby TV. Pathologic manifestations of bronchiolitis, constrictive bronchiolitis, cryptogenic organizing pneumonia, and diffuse panbronchiolitis. Clin Chest Med 1993;14:611-22.

101. Wells Cryptogenic organizing pneumonia. Sem Resp Crit Care M 2001;22:449-60.

102. Radzikowska E, Wiatr E, Langfort R, Bestry I, Skoczylas A, Szczepulska-Wójcik E, et al. Cryptogenic organizing pneumonia-Results of treatment with clarithromycin versus corticosteroids-Observational study. PLOS One 2017;12:e184739.

103. Mandel J, Mark EJ, Hales CA. Pulmonary Veno-occlusive Disease. Am J Resp Crit Care Med 2000;162:1964-73.

104. Hackman RC, Madtes DK, Petersen FB, Clark JG. Pulmonary venoocclusive disease following bone marrow transplantation. Transplantation 1989;47:989-92.

105. Woodard JP, Gulbahce E, Shreve M, Steiner M, Peters C, Hite S, et al. Pulmonary cytolytic thrombi: a newly recognized complication of stem cell transplantation. Bone Marrow Transplant 2000;25:293-300.

106. Gulbahce HE, Manivel JC, Jessurun J. Pulmonary cytolytic thrombi: a previously unrecognized complication of bone marrow transplantation. Am J Surg Pathol 2000;24:1147-52. 